\title{
Optimal Guiding Catheter Length for Endovascular Coiling of Intracranial Aneurysms in Anterior Circulation in Era of Flourishing Distal Access System
}

\author{
Zhen Yu Jia, MD',2, Sang Hun Lee, MD',3, Young Eun Kim, BS', Joon Ho Choi, BS', \\ Sun Moon Hwang, BS', Ga Young Lee, RN', Jin Ho Youn, BS', Deok Hee Lee, MD'
}

Purpose: To determine the minimum required guiding catheter length for embolization of various intracranial aneurysms in anterior circulation and to analyze the effect of various patient factors on the required catheter length and potential interaction with its stability.

Materials and Methods: From December 2016 to March 2017, 90 patients with 93 anterior circulation aneurysms were enrolled. Three types of guiding catheters (Envoy, Envoy DA, and Envoy DA XB; Codman Neurovascular, Raynham, MA, USA) were used. We measured the in-the-body length of the catheter and checked the catheter tip location in the carotid artery. We analyzed factors affecting the in-the-body length and stability of the guiding catheter system.

Results: The average ( \pm standard deviation) in-the-body length of the catheter was $84.2 \pm 5.9 \mathrm{~cm}$. The length was significantly longer in men $(89.1 \pm 5.6$ vs. $82.1 \pm 4.6 \mathrm{~cm}, \mathrm{P}<0.001)$, patients older than 65 years ( $87.7 \pm 7.8$ vs. $82.7 \pm 4.2 \mathrm{~cm}, \mathrm{P}<0.001)$, patients with a more tortuous arch (arch type 2 and 3 ) $(87.5 \pm 7.4$ vs. $82.7 \pm 4.4 \mathrm{~cm}, \mathrm{P}<0.001)$, and patients with a distal aneurysm location (distal group) $(86.2 \pm 5.0$ vs. $82.7 \pm 6.1 \mathrm{~cm}, \mathrm{P}=0.004)$. A shift in the tip location was noted in 19 patients $(20.4 \%)$; there was no significant different among the 3 catheters $(P=0.942)$.

Conclusion: The minimum required length of a guiding catheter was $84 \mathrm{~cm}$ on average for elective anterior-circulation aneurysm embolization. The length increased in men older than 65 years with a more tortuous arch. We could reach a higher position with distal access catheters with little difference in the stability once we reached the target location.

Key Words : Cerebral aneurysm; Endovascular treatment; Guiding catheter; Intermediate catheter; Distal access catheter

'Department of Radiology and Research Institute of Radiology, Asan Medical Center, Seoul, Korea

2Department of Radiology, The First Affiliated Hospital of Nanjing Medical University, Nanjing, China

${ }^{3}$ Department of Neurology, Korea University Ansan Hospital, Korea University College of Medicine, Ansan, Korea

Received July 31, 2017; Revised August 7, 2017; Accepted August 8, 2017.

This research was supported by a research grant from Korean Society of Interventional Neuroradiology.

Correspondence to: Deok Hee Lee, MD, PhD, Department of Radiology, Research Institute of Radiology, Asan Medical Center, University of Ulsan College of Medicine, 88, Olympic-ro 43-gil, Songpa-gu, Seoul 05505, Korea.

Tel. 82.2.3010.5944 Fax. 82.2.476.0090 E-mail: dhlee@amc.seoul.kr

This is an Open Access article distributed under the terms of the Creative Commons Attribution Non-Commercial License (http://creativecommons.org/licenses/by-nc/3.0) which permits unrestricted non-commercial use, distribution, and reproduction in any medium, provided the original work is properly cited. 


\section{Zhen Yu Jia, et al.}

The procedural outcome of endovascular aneurysm treatment has improved for ruptured and unruptured aneurysms owing to the improvement in embolization devices and embolic materials, and to the improvement in access technology, including guiding catheter systems. After introduction of the concept of the intermediate catheter system (Outreach; Concentric Medical, Mountainview, CA, USA) in the acute stroke revascularization procedure and then in aneurysm embolization as early as 2009 with the name of the distal access catheter or bridging catheter [1, 2], various types of intermediate catheter technologies have been introduced for many neurovascular procedures. In the manufacturing aspect, the technology has been possible because of enhanced flexibility of the large-bore catheter and softer, atraumatic catheter tip technology [3]. Even though the catheter was introduced for the acute stroke procedure, the catheter has helped improve the procedural safety and effectiveness of various technically demanding neurovascular procedures, including endovascular treatment of the aneurysms [49].

However, improvement in technology inevitably accompanies diversity of the devices, including the variable device length for fulfilling the purpose of each device (Table 1). Choosing the right guiding system for a certain procedure has become a matter of importance. Conventional guiding catheters only have a $90-\mathrm{cm}$ and $100-\mathrm{cm}$ working catheter length regardless of the outer diameter or inner diameter. Recently introduced distal access catheters have diversified lengths by adding 95 $\mathrm{cm}, 105 \mathrm{~cm}, 110 \mathrm{~cm}$, etc. Sometimes they are longer than that, especially with an intermediate catheter system. The choice of diameters and lengths of a guiding catheter has become a matter of concern even after choosing a certain guiding catheter system for the embolization procedure since the required length of the catheter can be different from patient to patient. The length can be diverse according to the patient's height, arterial tortuosity, aortic arch type, target lesion location, etc. Furthermore, we should consider an additional distal length required for further distal access in technically demanding situations that require more support and robust lesion access.

The purpose of this study was to determine the minimum required length of the conventional guiding catheter and distal access guiding catheter for the embolization of various intracranial aneurysms in the anterior circulation through the transfemoral approach. We analyzed the effect of various patient factors on the required guiding catheter length and potential interac- tion with the stability of the guiding system.

\section{MATERIALS AND METHODS}

\section{Patient and angiographic data}

From December 2016 to March 2017, 90 patients who had undertaken endovascular coil embolization of unruptured intracranial aneurysms in the anterior circulation through the right femoral artery approach were enrolled in this study. Two aneurysms in different locations of the anterior circulation were treated simultaneously in 3 patients. Since the required length of the guiding catheter will be different even in the same patient if the two aneurysms are in a different location, we counted these 3 patients with two aneurysms twice, resulting in 93 patients overall. From a retrospective review of patients' medical records, basic patient characteristics, including sex, age, history of hypertension, height, and weight, were obtained. Regarding the target aneurysm and arterial anatomic characteristics, we analyzed the anatomic location of the aneurysm, laterality in the carotid system (right or left), and type of aortic arch. Since all patients had intradural aneurysms located in the anterior circulation, we categorized the aneurysm into two groups: aneurysms located in the intradural internal carotid artery (ICA) (proximal group) or aneurysms located beyond the terminal ICA bifurcation (distal group). Classification of the arch type was done using the previously suggested criteria $[10,11]$.

\section{Arterial access and guiding catheter insertion}

Each procedure was performed by two neurointerventionists separately. Under general anesthesia, a 6French (F) arterial access sheath (Accu-Sheath; Sungwon Medical, Chungbuk, Korea) was introduced through the right femoral artery route. A 6-F guiding catheter was introduced into the target artery. We used three different methods of arterial access to the target: insertion of the guiding catheter directly over a guidewire (direct method), advancement of the guidewire together with a 4-F diagnostic catheter (coaxial method), or delivery of the guiding catheter over a long exchange wire (exchange method). Three different kinds of guiding catheters were available: the Envoy (Codman Neurovascular, Raynham, MA, USA), Envoy DA (DA, Codman Neurovascular), or Envoy DA XB (Codman Neurovascular). The choice of the access method and type and length of the guiding catheter was solely dependent on the individual neurointerventionist's discretion considering the patient's height, lesion 


\begin{tabular}{|c|c|c|c|c|c|c|c|c|c|c|c|c|}
\hline 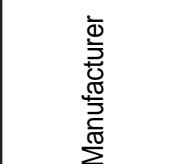 & 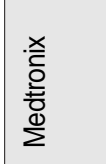 & 产 & 产 & $\begin{array}{l}\text { 뜰 } \\
\text { 흥 } \\
0\end{array}$ & & & 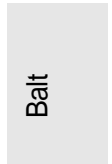 & $\begin{array}{l}\text { 套 } \\
\text { 言 } \\
\text { 恶 }\end{array}$ & 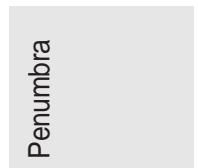 & $\begin{array}{l}\text { 듀 } \\
\text { 흥 } \\
\text { O }\end{array}$ & 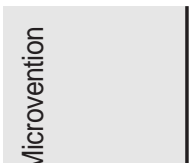 & \\
\hline 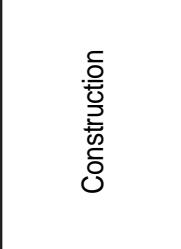 & \begin{tabular}{|l}
$\overline{\bar{z}}$ \\
$\bar{o}$ \\
产 \\
$\bar{z}$
\end{tabular} & 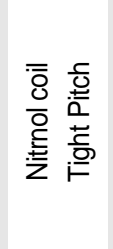 & 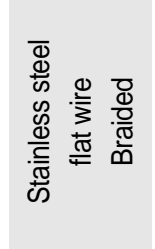 & 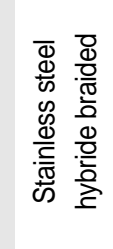 & 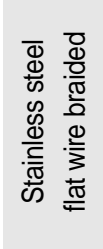 & 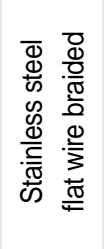 & 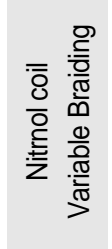 & 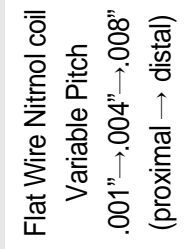 & 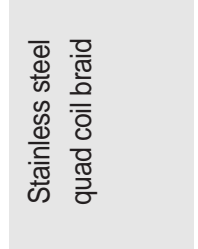 & 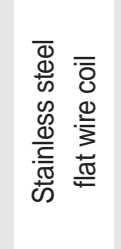 & 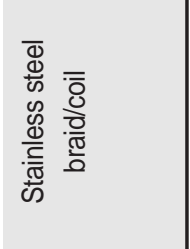 & \\
\hline 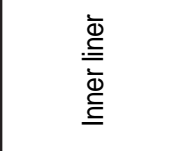 & 店 & 岕 & 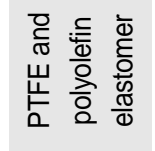 & 㟒 & 店 & 岕 & 店 & 㟒 & 崖 & 店 & 岁 & \\
\hline 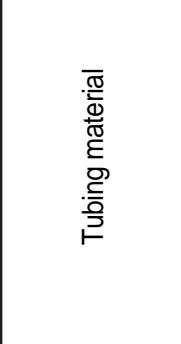 & 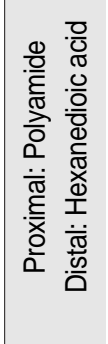 & 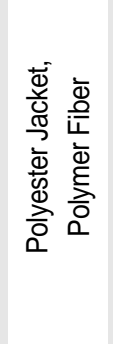 & 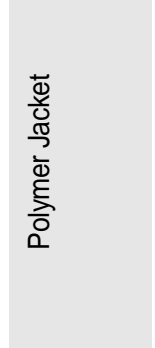 & 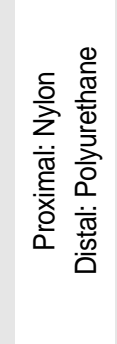 & 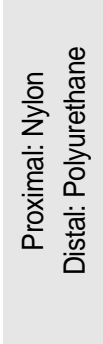 & 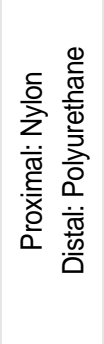 & $\Sigma$ & 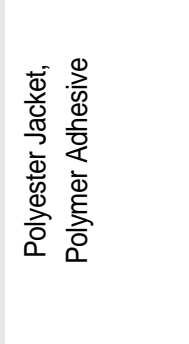 & 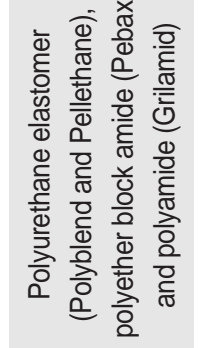 & 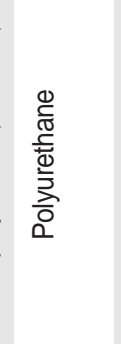 & 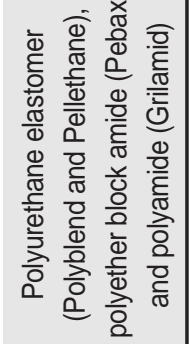 & \\
\hline 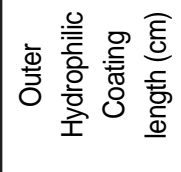 & $\bar{z}$ & $\underset{\infty}{E}$ & 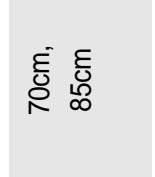 & 2 & 틍 & 틍 & 틍 & Е్ & $\stackrel{E}{\stackrel{0}{ }}$ & 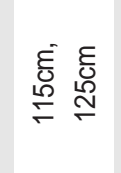 & 틍 & \\
\hline 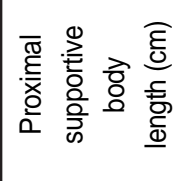 & $\Sigma$ & 듬 & 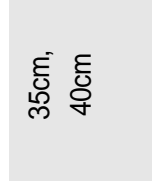 & 톰 & 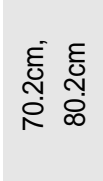 & 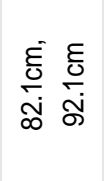 & $\Sigma$ & $\bar{z}$ & 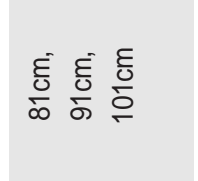 & $\begin{array}{l}\text { E్ } \\
\stackrel{\infty}{\infty} \\
\text { E } \\
\infty \\
\infty\end{array}$ & 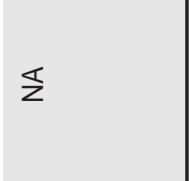 & \\
\hline 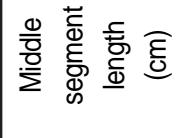 & $\Sigma$ & $\begin{array}{l}\underset{\mathscr{O}}{\mathscr{O}} \\
\text { }\end{array}$ & 릉 & हัँ & 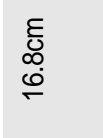 & 产 & $\underline{z}$ & $\Sigma$ & Е్ & $\begin{array}{l}\underset{E}{E} \\
\stackrel{0}{\stackrel{0}{\rho}}\end{array}$ & $\Sigma$ & \\
\hline 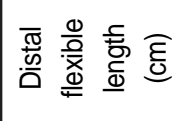 & 틍 & 导 & हू & z & ్్ㅇ & Е్ & 总 & 틍 & 등 & ్ㅡㅁ & 틍 & \\
\hline 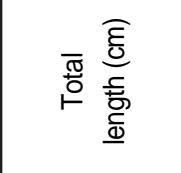 & 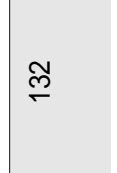 & 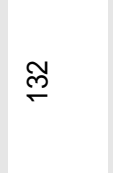 & 옹 & $\frac{8}{8}$ & $\frac{80}{\circ}$ & $\begin{array}{l}\stackrel{80}{0} \\
\stackrel{8}{\circ}\end{array}$ & 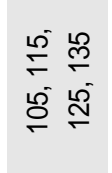 & $\begin{array}{l}\stackrel{20}{=} \\
\text { 응 }\end{array}$ & 용 & 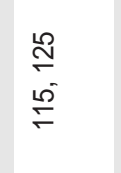 & $\begin{array}{l}\bar{m} \\
\stackrel{\mathfrak{N}}{\alpha}\end{array}$ & \\
\hline 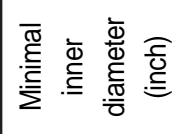 & $\begin{array}{l}\overline{\bar{o}} \\
\overline{0} \\
\dot{0}\end{array}$ & : & 高 & 产 & 定 & 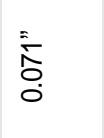 & 总 & 产 & م. & : & م. & \\
\hline 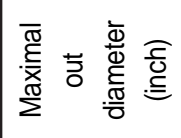 & ồ & $\begin{array}{l}5 \\
0 \\
0 \\
0 \\
0\end{array}$ & 离 & $\begin{array}{l}0 \\
\text { ò } \\
0 \\
0\end{array}$ & ö & $\begin{array}{l}\text { oे } \\
\text { o̊ } \\
0\end{array}$ & $\begin{array}{l}5 \\
\vdots \\
0 \\
0 \\
0\end{array}$ & 㕉 & $\begin{array}{l}0 \\
\text { o. } \\
0 \\
0\end{array}$ & $\begin{array}{l}\hat{1} \\
\text { ö } \\
0\end{array}$ & $\begin{array}{l}\text { in } \\
00 \\
0 \\
0\end{array}$ & \\
\hline $\begin{array}{l}\overline{\bar{\sigma}} \\
\overline{\mathrm{D}}\end{array}$ & 忘 & 忘 & $\begin{array}{l}\text { 忘 } \\
\text { \& }\end{array}$ & & & & & 忘 & & 守 & 占 & \\
\hline & 忘 & 忘 & 忘 & 忘 & 忘 & 忘 & 忘 & 忘 & 忘 & 忘 & 忘 & \\
\hline 홈 & 昰 & 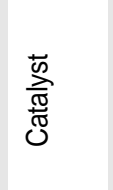 & 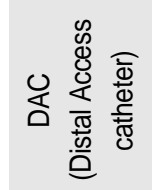 & 离 & $\begin{array}{l}\text { a } \\
\text { Dे } \\
\text { W }\end{array}$ & 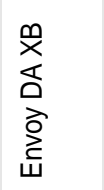 & 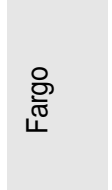 & 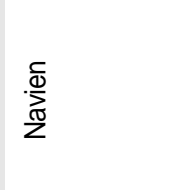 & 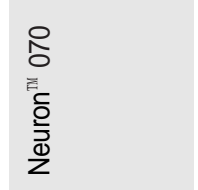 & 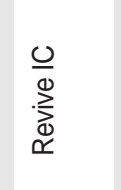 & $\begin{array}{l}\text { 雨 } \\
\text { ch }\end{array}$ & \\
\hline
\end{tabular}




\section{Zhen Yu Jia, et al.}

location, and arterial tortuosity of the access route. After placing the guiding catheter in the desired location of the ICA segment, successive steps of the embolization procedure were performed as planned.

\section{Measurement of the catheter length and data analysis}

After successful placement of the guiding catheter at the aimed position in the carotid system, we measured the out-of-the-body length of the guiding catheter right before microcatheter insertion. By measuring the length from the hub of the introducer sheath to the release of tension of the guiding catheter, we could calculate the in-the-body length of the guiding catheter, which could be considered as the minimum required length of the guiding catheter, since the total length of the catheter was already known. As we could observe downward displacement of the guiding catheter tip during the procedure, we measured the length once again by using the same method right after the completion of embolization before completing angiography to assess stability of the guiding system during the embolization procedure.

To quantify the location of the guiding catheter tip within the target carotid artery, we segmented and numbered the artery from the distal common carotid artery to the intradural distal ICA arbitrarily (Fig. 1). The location of the catheter tip was checked when the out-of-the-body catheter length was measured. Any change of the tip location during the interval of the two measurements was checked. Since the purpose of the two distal access catheters (Envoy DA and Envoy DA $\mathrm{XB})$ were access to the higher position than the conventional guiding catheter, we analyzed the difference in the guiding catheter tip location among the types of guiding catheters by dichotomizing the location by the carotid genu of the petrous segment for statistical testing: below the genu (segments 1-5) and above the genu (segments 6-8). We checked whether the distal location of the aneurysm (distal group vs. proximal group) required a higher tip position. The need to switch the guiding catheter was noted.

Since we considered that downward displacement of the catheter tip could be due to instability of the guiding system, we checked the presence of any difference in the segment numbers between the preprocedure and post-procedure to compare the performance of the three guiding catheter systems. We also analyzed several potential factors affecting the stability of the guiding system, such as use of the stent, arch type, lesion laterality, and initial location of the tip. We used the t-test and analysis of variance to compare the means and Fisher exact test for the cross-table analyses using a statistical analysis package (SPSS version 11; SPSS, Inc., Chicago, IL, USA).

\section{RESULTS}

\section{In-the-body length of the guiding catheter}

Basic patient demographic and procedural characteristics are summarized in Table 2. All embolization procedures were performed successfully. All the counted and calculated numbers were on a per aneurysm basis. The method we used to advance the guiding catheter system to the target was different among the systems (Table 3). The conventional Envoy DA and DA XB guiding systems showed a higher rate of successful target access when advancement was tried with the catheter alone. The average in-the-body length of the catheter regardless of the type of guiding catheter was $84.2 \pm 5.9 \mathrm{~cm}$. The length was significantly longer in men $(89.1 \pm 5.6$ vs. $82.1 \pm 4.6 \mathrm{~cm}, \mathrm{P}<0.001)$, patients older than 65 years $(87.7 \pm 7.8$ vs. $82.7 \pm 4.2 \mathrm{~cm}$,

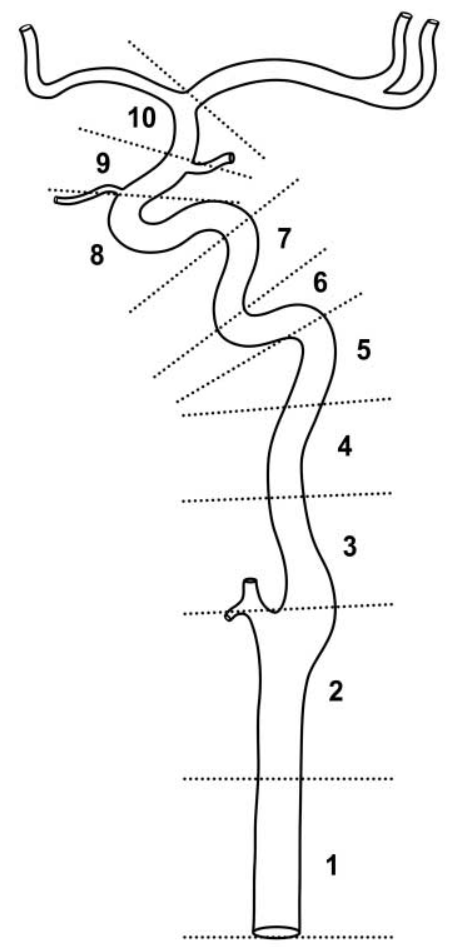

Fig. 1. A schematic diagram showing arbitrary segmentation of the carotid artery from the distal common carotid artery to the intradural internal carotid artery right below the bifurcation (segments 1 to 8 ). We dichotomized the segments into the lower position (segments 1 to 5 ) and higher position (segments 5 to 8 ) using the genu of the petrous segment of the internal carotid artery as the landmark. 


\section{Optimal Guiding Catheter Length for Aneurysms Coiling}

Table 2. Summary of the Demographic and Procedural Characteristics of the 93 Patients

\begin{tabular}{|c|c|c|}
\hline Female, n (\%) & & $66(71.0 \%)$ \\
\hline Mean age $\pm S D, y$ & & $58.3 \pm 9.9$ \\
\hline Mean height $\pm S D, c m$ & & $158.8 \pm 8.2$ \\
\hline Mean weight $\pm S D$, $\mathrm{kg}$ & & $62.0 \pm 9.8$ \\
\hline Hypertension, n (\%) & & $43(46.2 \%)$ \\
\hline \multicolumn{3}{|l|}{ Guiding catheter } \\
\hline & Envoy, n (\%) & $51(54.8 \%)$ \\
\hline & Envoy DA, n (\%) & $15(16.1 \%)$ \\
\hline & Envoy XB DA, n (\%) & $28(30.1 \%)$ \\
\hline Lesion laterality, right, $\mathrm{n}(\%)$ & & $41(44.1 \%)$ \\
\hline \multicolumn{3}{|c|}{ Guiding catheter insertion technique } \\
\hline & Direct insertion & $80(86.0 \%)$ \\
\hline & Coaxial system & $11(11.8 \%)$ \\
\hline & Exchange technique & $2(2.2 \%)$ \\
\hline \multicolumn{3}{|l|}{ Arch type } \\
\hline & Type 1 & $63(67.7 \%)$ \\
\hline & Type 2 & $29(31.2 \%)$ \\
\hline & Type 3 & $1(1.1 \%)$ \\
\hline \multicolumn{3}{|l|}{ Aneurysm location } \\
\hline & Intradural ICA & $52(55.9 \%)$ \\
\hline & ACoA & $19(20.4 \%)$ \\
\hline & MCA & $15(16.1 \%)$ \\
\hline & ACA & $7(7.5 \%)$ \\
\hline Stent assisted coiling, n (\%) & & $34(36.6)$ \\
\hline \multicolumn{3}{|c|}{ Initial guiding catheter tip location (segment) in the ICA } \\
\hline & $1, \mathrm{n}(\%)$ & 0 \\
\hline & $2, \mathrm{n}(\%)$ & 0 \\
\hline & $3, \mathrm{n}(\%)$ & $2(2.2 \%)$ \\
\hline & $4, \mathrm{n}(\%)$ & $11(11.8 \%)$ \\
\hline & $5, \mathrm{n}(\%)$ & $48(51.6 \%)$ \\
\hline & $6, \mathrm{n}(\%)$ & $22(23.7 \%)$ \\
\hline & $7, \mathrm{n}(\%)$ & $8(8.6 \%)$ \\
\hline & $8, \mathrm{n}(\%)$ & $2(2.2 \%)$ \\
\hline \multicolumn{3}{|c|}{ Guiding catheter tip displacement during procedure } \\
\hline & Stable position, n (\%) & $74(79.6 \%)$ \\
\hline & Kickback, n (\%) & $7(7.5 \%)$ \\
\hline & Withdrawal due to arterial spasm, n (\%) & $9(9.7 \%)$ \\
\hline & Intentional pull back, n (\%) & $3(3.2 \%)$ \\
\hline
\end{tabular}

SD: standard deviation 
$\mathrm{P}<0.001)$, patients with a more tortuous arch (arch types 2 and 3$)(87.5 \pm 7.4$ vs. $82.7 \pm 4.4 \mathrm{~cm}, \mathrm{P}<0.001)$, and patients with a distal aneurysm location (distal group) $(86.2 \pm 5.0$ vs. $82.7 \pm 6.1 \mathrm{~cm}, \mathrm{P}=0.004)$. Laterality of the aneurysm in the carotid system (the lesions in the right carotid system and those in the left carotid system) and presence of hypertension did not show significant difference in the required catheter length. There were significant differences in the length according to the type of the guiding catheter (Table 4). Distal access catheters (Envoy DA and Envoy DA XB) showed a significantly longer in-the-body length than conventional guiding catheters (Envoy) $(87.3 \pm 6.6 \mathrm{vs}$. $81.8 \pm 3.9 \mathrm{~cm}, \mathrm{P}<0.001)$. As was expected, the in-thebody length of the catheters was significantly shorter when the length was measured right before completing angiography $(84.2 \pm 5.9 \mathrm{~cm}$ vs. $83.6 \pm 6.4 \mathrm{~cm}$, $\mathrm{P}<0.001$ ). Means and standard deviations of the in-thebody lengths of the guiding systems are summarized in Table 5.

\section{Location of the guiding catheter tip and stability of the guiding system}

The guiding catheter system needed to be switched in 2 patients: one from the conventional Envoy to the Envoy DA XB due to tortuosity of the ICA, which showed significant focal spasm caused by the tip of the Envoy catheter; and the other from the Envoy DA to the Envoy DA XB due to instability of the guiding system during microcatheter insertion. Table 6 shows the locations of the tip of each type of guiding catheters. When the distribution pattern was dichotomized as higher (segment 6 or higher) and lower (segment 5 or below) positions, $46.2 \%$ of patients with the Envoy DA, $66.7 \%$ of patients with the Envoy DA XB, and only $15.1 \%$ of patients with the regular Envoy had a higher position $(\mathrm{P}<0.001)$. A shift in the tip location was noted in 19 patients $(20.4 \%)$, and there was no significant different among the 3 guiding catheter systems $(\mathrm{P}=0.942)$. There was no significant difference in the percentage of instability of the guiding catheter system

Table 3. Difference in Guiding Catheter Advancement Method Among the 3 Guiding Systems

\begin{tabular}{lcccc}
\hline Advancement method & Conventional Envoy $(\mathrm{n}, \%)$ & Envoy DA $(\mathrm{n}, \%)$ & Envoy XB DA (n, \%) & Total $(\mathrm{n})$ \\
\hline Direct advancement & $50(94.3 \%)$ & $7(53.8 \%)$ & $23(85.2 \%)$ & 80 \\
Coaxial method & $3(5.7 \%)$ & $6(46.2 \%)$ & $2(7.4 \%)$ & $2(7.4 \%)$ \\
Exchange method & 0 & 0 & 2 \\
\hline
\end{tabular}

Table 4. The Difference in the in-the-body Length of the 3 Guiding Systems

\begin{tabular}{lccc}
\hline Guiding system & Number & Mean $(\mathrm{cm})$ & Standard deviation $(\mathrm{cm})$ \\
\hline Envoy & 53 & 81.8 & 3.9 \\
Envoy DA & 13 & 86.0 & 6.5 \\
Envoy XB DA & 27 & 88.0 & 6.6 \\
\hline
\end{tabular}

Table 5. Mean in-the-body Length in 93 Patients

\begin{tabular}{|c|c|c|c|}
\hline Parameters & $\mathrm{n}$ & In-the-body length (cm, mean $\pm \mathrm{SD}$ ) & $P$ value \\
\hline Average length before procedure & 93 & $84.2 \pm 5.9$ & - \\
\hline Male vs. female & 27 vs. 66 & $89.1 \pm 5.6$ vs. $82.1 \pm 4.6$ & $\mathrm{p}<0.001$ \\
\hline Older vs. younger than 65 & 27 vs. 66 & $87.7 \pm 7.8$ vs. $82.7 \pm 4.2$ & $\mathrm{p}<0.001$ \\
\hline Hypertension; yes and no & 43 vs. 50 & $85.4 \pm 6.5$ vs. $83.2 \pm 5.1$ & $P=0.073$ \\
\hline Lesion laterality; right vs. left & 41 vs. 52 & $84.6 \pm 6.6$ vs. $83.9 \pm 5.3$ & $P=0.982$ \\
\hline Guiding system; conventional vs. distal access system & 53 vs. 40 & $81.8 \pm 3.9$ vs. $87.3 \pm 6.6$ & $p<0.001$ \\
\hline Arch type; 1 vs. 2 or 3 & 63 vs. 30 & $82.7 \pm 4.4$ vs. $87.5 \pm 7.4$ & $p<0.001$ \\
\hline Aneurysm location; proximal vs. distal & 52 vs. 41 & $82.7 \pm 6.1$ vs. $86.2 \pm 5.0$ & $P=0.004$ \\
\hline Average length after procedure & 93 & $83.6 \pm 6.4$ & - \\
\hline
\end{tabular}




\section{Optimal Guiding Catheter Length for Aneurysms Coiling}

Table 6. The Distribution of Tip Locations According to the Type of Guiding Catheter

\begin{tabular}{lcccc}
\hline Tip location & Envoy, n (\%) & Envoy DA, n (\%) & Envoy XB DA, n (\%) & Total, n (\%) \\
\hline Total & 53 & 13 & 27 & 93 \\
Segment 8 & $1(1.9 \%)$ & $0(0 \%)$ & $1(3.7 \%)$ & $2(2.2 \%)$ \\
Segment 7 & $1(1.9 \%)$ & $1(7.7 \%)$ & $6(22.2 \%)$ & $8(8.6 \%)$ \\
Segment 6 & $6(11.3 \%)$ & $5(38.5 \%)$ & $11(40.7 \%)$ & $22(23.7 \%)$ \\
Segment 5 & $36(67.9 \%)$ & $4(30.8 \%)$ & $8(29.6 \%)$ & $48(51.6 \%)$ \\
Segment 4 & $8(15.1 \%)$ & $2(15.4 \%)$ & $1(3.7 \%)$ & $11(11.8 \%)$ \\
Segment 3 & $1(1.9 \%)$ & $1(7.7 \%)$ & $0(0 \%)$ & $2(2.2 \%)$ \\
Segment 2 & $0(0 \%)$ & $0(0 \%)$ & $0(0 \%)$ & $0(0 \%)$ \\
Segment 1 & $0(0 \%)$ & $0(0 \%)$ & $0(0 \%)$ & $0(0 \%)$ \\
\hline
\end{tabular}

(any change in the tip location) between the procedures with stent assistance and without stent assistance ( $18.6 \%$ vs. $23.5 \%, \mathrm{P}=0.574)$. There was no significant change of the tip location according to lesion laterality (right and left, $19.5 \%$ vs. $21.2 \%, \mathrm{P}=0.845$ ) or aortic arch type (types 1,2 , and $3,19.0 \%$ vs. $23.3 \%$, $\mathrm{P}=0.294)$.

\section{DISCUSSION}

The term distal access catheter can be used for the guiding catheter, which was designed to achieve more distal access than a conventional guiding catheter, or for the intermediate catheter, which had extra-flexibility and could be used coaxially within a large-bore long sheath or conventional guiding catheter. Intermediate catheters have been used as an effective system in various neurovascular procedures such as brain arteriovenous malformation embolization $[5,6,12]$, the intracranial stenting procedure, or aneurysm embolization $[2,4,8,9]$. These catheters have been successfully used in various intra-arterial revascularization procedures as an aspiration catheter system or an effective intermediate catheter system for the delivery of stentrievers [13-16]. However, these catheters are not suitable to use as a sole guiding catheter system due to the lack of a sufficient supportive body segment. In this study, we limited the type of catheter to the narrowed meaning of the distal access catheter, which can be used as a guiding catheter independently, to focus our primary study purpose of analyzing the required in-the-body length of conventional and distal access guiding systems.

We found that the average required in-the-body length of a guiding catheter for embolization of the aneurysm in the anterior circulation was about $84 \mathrm{~cm}$ on average. A longer length was anticipated in male patients when the target aneurysm was located distally, when the arterial access route was tortuous, or with advanced age $[10,11]$. Laterality in the carotid system or history of hypertension did not show any effect on the catheter length. Although the average lengths were still shorter than $90 \mathrm{~cm}$ in most patients, the $105-\mathrm{cm}$ system could be short in case of the worst combination of factors, such as a male patient of advanced age with a distally located target aneurysm and tortuous aortic arch.

Since the purpose of the distal access catheter system, such as the Envoy DA and Envoy DA XB, was stable distal access to the target, we noted a significant longer in-the-body length in them that was owed to effective distal access with these systems. Interestingly, the use of multiple devices, lesion laterality, and arch type did not show any effect on the stability of the guiding catheter system. We thought that this was due to the durable stability of the Envoy guiding system once the tip was placed at the target portion. The Envoy DA was released in the market as the first distal access system that was modified from the conventional Envoy guiding catheter by adding a long flexible distal segment for better adjustment to the tortuosity of the supra-aortic vessels hopefully beyond the petrous segment of the ICA or foraminal segment of the vertebral arteries. However, due to the exaggerated flexibility of the distal segment, navigating the aortic arch became challenging with the Envoy DA compared with the conventional Envoy catheter and often required the coaxial or exchange method in advancement to the target location. Furthermore, the flexible distal segment tended to decrease back support capability in some patients. 


\section{Zhen Yu Jia, et al.}

These problems could be minimized by limiting the flexible segment less than $10 \mathrm{~cm}$ and enhancing the stiffness of the main body as we could see with the Envoy DA XB system. As of now, our preferred distal access system is the Envoy DA XB. Use of the Envoy DA is reserved for patients with an extremely tortuous ICA, as fewer problems are expected below the arch vessels. The conventional Envoy catheter is still chosen as the main guiding catheter in less challenging situations.

There was an obvious difference between the Envoy DA and Envoy DA XB in several aspects, even though both were developed for the same purpose: efficient distal access. The difference seemed to be due to the difference in the length of the distal flexible or soft segment. It is notable that we choose to use the Envoy DA in only $14 \%$ of patients, and the coaxial method was used in about half of the patients who received the Envoy DA; this finding may suggest that the Envoy DA has a lower performance than the Envoy DA XB. This result might also imply that a shorter distal flexible segment would be enough to access the anterior circulation if the tip of the catheter was atraumatic. Too long of a flexible distal segment of the Envoy DA system might serve as a barrier to arch vessel selection and decreased back support capability of the guiding catheter system [17].

Since we chose patients who underwent elective embolization of unruptured aneurysms, there were not many patients with marked tortuosity of the large arteries, which might hinder successful lesion access and require a longer catheter to reach the target due to inevitable redundancy of the aorta and supra-aortic arteries caused by tortuosity. We believe a similar measurement study of the carotid artery stenting procedure or intracranial revascularization procedure would provide a different result since these patient cohorts may show more severe arterial tortuosity. Although we did not experience procedural difficulty in our patient cohort, a longer in-the-body length would be a surrogate indicator of procedural difficulty in these revascularization procedures [10].

One main limitation of this study would be the limited use of guiding catheters from only one company, resulting in a lack of diversity. However, limiting the study devices to the catheters with a similar platform helped us understand differences in the performance of each catheter with ease, as we discussed earlier.

Another limitation of this study was in the practical aspect of using guiding catheters to prevent catheter tip-related focal vasospasm in the ICA. Due to the retrospective nature of this study, we could not analyze the difference among the three guiding catheter systems. In a percentage of patients, we should have pulled back the tip of the guiding catheter due to flowlimiting focal vasospasm. Even though the phenomenon was observed more frequently with the conventional Envoy catheter, we could not present the difference due to the lack of complete data.

We found that the minimum required length of a guiding catheter was $84 \mathrm{~cm}$ on average for elective anterior circulation aneurysm embolization with the transfemoral approach. A longer length was seen in men, patients older than 65 years, patients with a more tortuous arch, and patients with a distal aneurysm location. We could reach a higher position with distal access catheters with little difference in the stability of the guiding catheter system regardless of the type of the catheter once we reached the target location.

\section{References}

1. Kalia JS, Zaidat OO. Using a distal access catheter in acute stroke intervention with penumbra, merci and gateway. A technical case report. Interv Neuroradiol 2009;15:421-424

2. Velat GJ, Lawson MF, Hoh BL, Mocco J. Novel application of an intermediate sized bridging catheter as an adjunct to aneurysm coiling in patients with tortuous vasculature. Interv Neuroradiol 2009; $15: 448-452$

3. Hui FK, Schuette AJ, Spiotta AM, Yim J, Obuchowski N, Rasmussen PA, et al. Flexible tip guides and intermediate catheters: two center experience and a proposed taxonomy. $J$ Neurointerv Surg 2014;6:618-623

4. Hauck EF, Tawk RG, Karter NS, Binning MJ, Khalessi AA, Natarajan SK, et al. Use of the outreach distal access catheter as an intracranial platform facilitates coil embolization of select intracranial aneurysms: technical note. J Neurointerv Surg 2011; 3:172-176

5. Spiotta AM, Hussain MS, Sivapatham T, Bain M, Gupta R, Moskowitz SI, et al. The versatile distal access catheter: the Cleveland Clinic experience. Neurosurgery 2011;68:1677-1686; discussion 86

6. Binning MJ, Yashar P, Orion D, Hauck EF, Levy EI, Hopkins LN, et al. Use of the Outreach Distal Access Catheter for microcatheter stabilization during intracranial arteriovenous malformation embolization. AJNR Am J Neuroradiol 2012;33: E117-119

7. Lin LM, Colby GP, Huang J, Tamargo RJ, Coon AL. Ultra-distal large-bore intracranial access using the hyperflexible Navien distal intracranial catheter for the treatment of cerebrovascular pathologies: a technical note. J Neurointerv Surg 2014;6:301-307

8. Wang D, Wang Y, Su W, Wang Y, Li G, Li X. A novel approach using Neuron $6 \mathrm{~F}$ guiding catheter for the embolization of intracranial aneurysm with coiling of the parent internal carotid artery. Int J Clin Exp Med 2015;8:1534-1539 


\section{Optimal Guiding Catheter Length for Aneurysms Coiling}

9. Colby GP, Lin LM, Xu R, Beaty N, Bender MT, Jiang B, et al. Utilization of a Novel, Multi-Durometer Intracranial Distal Access Catheter: Nuances and Experience in 110 Consecutive Cases of Aneurysm Flow Diversion. Interv Neurol 2017;6:90-104

10. Lam RC, Lin SC, DeRubertis B, Hynecek R, Kent KC, Faries PL. The impact of increasing age on anatomic factors affecting carotid angioplasty and stenting. J Vasc Surg 2007;45:875-880

11. Burzotta F, Nerla R, Pirozzolo G, Aurigemma C, Niccoli G, Leone AM, et al. Clinical and procedural impact of aortic arch anatomic variants in carotid stenting procedures. Catheter Cardiovasc Interv 2015;86:480-489

12. Puri AS, Kuhn AL, Hou SY, Wakhloo AK. Use of intermediate guide catheters as an adjunct in extracranial embolization to avoid onyx reflux into the anastomotic vasculature. A technical note. Interv Neuroradiol 2014;20:424-427

13. Lee HC, Kang DH, Hwang YH, Kim YS, Kim YW. Forced Arterial Suction Thrombectomy Using Distal Access Catheter in
Acute Ischemic Stroke. Neurointervention 2017;12:45-49

14. Shallwani H, Shakir HJ, Rangel-Castilla L, Davies JM, Sonig A, Sattur MG, et al. Safety and Efficacy of the Sofia (6F) PLUS Distal Access Reperfusion Catheter in the Endovascular Treatment of Acute Ischemic Stroke. Neurosurgery. 2017

15. Stampfl S, Kabbasch C, Muller M, Mpotsaris A, Brockmann M, Liebig $\mathrm{T}$, et al. Initial experience with a new distal intermediate and aspiration catheter in the treatment of acute ischemic stroke: clinical safety and efficacy. J Neurointerv Surg 2016;8:714-718

16. Wong JH, Do HM, Telischak NA, Moraff AM, Dodd RL, Marks $\mathrm{MP}$, et al. Initial experience with SOFIA as an intermediate catheter in mechanical thrombectomy for acute ischemic stroke. $J$ Neurointerv Surg. 2016

17. Al-Mufti F, Amuluru K, Singh IP, Gandhi C, Prestigiacomo CJ. Pipeline embolization device deployment via an envoy distal access XB guiding catheter-biaxial platform: a technical note. Interv Neuroradiol 2016;22:236-239 